\title{
ERP and E-Commerce Association Study
}

\author{
Jianfeng Lu \\ College of Finance and Trade, Bohai University, Jinzhou, 121013, China \\ lujianfeng9999@126.com
}

Keywords: ERP; E-Business; relativity; conformity

\begin{abstract}
ERP and electronic business is as IT technical generation and development gradually evolved, and they will help the operation itself IT, IT can be said that they are the foundation of root in IT, which is based on IT to grow on out of the two big tree, their respective and IT makes them close correlation between are born with great relevance. ERP and the son of the phase of close business affairs from two of the hair is the machine close. This thesis constructs ERP and EB's conformity model (EB-ERP) which explains that both of them operate in a holistic mode in a company. Based on EB-ERP, this thesis builds up integrative management module of production, supply and marketing, module of Customer Relation Management (CRM), module of Knowledge Management (KM) which analyses these management functions' idiographic operation mode when ERP and EB are integrated.
\end{abstract}

\section{Introduction}

We have entered into an information society in 21st Century. With the swift development of computer technology and Internet technology the operation mode of any company has a qualitative change. To win the competition, company begins to change from relying on production scale and product's price to satisfy the diversification and individuation of customer and respond to the market demand quickly. Speed becomes a key character in enterprise competition. The two kinds of modern business operation mode, ERP and E-business, get use of present advanced information technology (IT) to make the efficiency of business operation step up.

EB-ERP (the ERP system which added electronic business function) solution is the idea that ERP is a relatively mature enterprise management mode, and electronic business affairs is a new kind of enterprise operation mode, the electronic business integration with ERP, realizing the both internal organic integration [1,2]. First of all, this integration solution can make ERP and electronic commerce achieving a fully integrated. Second, through the stable mature, powerful ERP system drive e-commerce system work, can make the merger of the two to achieve the best effect., in the existing ERP software integration e-commerce and the promotion of the cost of this integration of EB relatively is lower, the operation more feasible.

\section{ERP and Electronic Business Related to the Specific Performance}

(1) Based on SCM compatibility. Generally speaking, there are three types of enterprises in flow: logistics, cash flow and information flow, among them, the information flow is not exist alone, it is closely related to logistics and cash flow, to reflect the flow of materials and money before, and the condition of the flow after the flow. Corresponding to the three kinds of flow respectively in three supply chain, namely material supply chain, capital supply chain and information supply chain. The e-commerce mainly involves the purchase and sale business, so online purchasing and online sales will be the enterprise new logistics and new part of the capital.

(2) Based on the relevance of CRM. CRM is ERP system of a extending direction in the future. CRM will not only the sales process automation, and help enterprise to make full use of key customers and enterprise data to optimize business decision-making process. CRM customers and enterprise to communicate ability, and the communication is through the electronic business model. Electronic commerce system for the customer and the operation of the enterprise of communication between provides intermediary, to provide direct ERP data. E-commerce is a kind of to the 
customer is the most convenient and of business enterprises, the highest cost-effective communication carrier.

(3) Based on business process of the auxiliary. ERP system function in enterprise's whole business process, its application levels have three: decision-making of data query and comprehensive analysis, the middle management and control, assignments of the realization of the business. And e-commerce will provide auxiliary support to all levels, for example, for assignment layer is concerned, can provide for marketing online advertising, online consumption released questionnaire investigation, assistant method.

(4) Based on application fields. According to the enterprise is the internal and external conditions, the enterprise in the introduction of e-commerce, won't be completely abandoned the traditional purchasing and sales model, but two kind of mode, two system in together and complement each other.

\section{ERP in the Electronic Commerce in the Construction of Advantage}

In order to improve the market competition ability, and many enterprises in implement internal information management at the same time, are active in the field of electronic commerce development, and ERP as a can effectively promote the enterprise management toward more scientific, reasonable and standardization direction of development method, be more enterprise in time control and application. Enterprise established in electronic business model of the process, the most important is the core of construction business management and application system, and the system is the most representative of enterprise internal ERP system. ERP is the informationization of the computer to realize scientific management thought, it to product development and design, operation control, production planning, investment tastes purchase, market marketing, sales, inventory, finance and personnel, etc, and the corresponding module component of the modes of the integrated optimization to management. ERP is not mechanical to adapt to the enterprise existing process, but the enterprise process unreasonable part put forward the improvement and optimization proposals, and could lead to the organization's redesign and business process reorganization. Therefore, the electronic commerce shall establish in ERP basis, both between and are not independent of each other, and they should be organically relates in together understanding. ERP in help enterprise electronic commerce construction has the following advantages [3,4].

System range widely. Enterprise in the construction of the electronic business process, the possible need to pass the decision-making and synthetic analysis of data inquires, the middle management and control, assignments of realization, the business of several business process, in this several process ERP system are plays a very important role.

Internal modules can be free configuration. Because of ERP software system in the design and development process of the internal each subsystem is modular, and these internal modules can be independent, enterprise in the modular system free of clipping and new configuration, and need according to oneself or this unit the characteristics of dollars, the system of different level selection and configuration, such as the number of internal system to general ledger accounts, bank accounts, such as accounts department function selection of targeted. So, ERP for enterprises to establish the electronic commerce system provides flexible foundation.

Can provide various flexible e-commerce solutions. In order to quickly establish a highly effective quick electronic business plan, ERP software can provide various flexible solutions: first is to plug in ERP system of CRM function module, if lets the enterprise sets up, business network store module; And then can plug in ERP system of SCM function module, but according to the real-time supply chain information to realize the function such as order; Finally, the software to help provide intermediary business integration front end and back end information, help enterprise to internal and external information integrated realm.

To assist enterprise quickly control the market information. In the fierce competition of the market environment, the enterprise needs to through continuous to get the latest market information to change itself, to develop their own. A new generation of management software should be able to support or help enterprise through all kinds of ways and methods to quickly master market 
information, such as sales management, order management, deliver goods transportation, invoice management, information, again through to these information in time to deal with customer requirements to make the most rapid reaction, make enterprise can in the shortest possible time rapidly readjust operation strategy or development direction. ERP with existing operation mode, can quickly to help enterprise to achieve this, greatly reduced the trouble back at home of electronic commerce.

Can solve the language barrier. With more and more businesses to trade, the direction of cross-border development, enterprise's management and international trade inevitable requirement too many kinds of language ERP system can support. In this case, ERP system should be set according to the user, in different client shows in different languages application interface. This can also lead put out another function, which can be made by users to set the system output interface on the terms of use and interface pattern, form the user interface of personalized, makes the different levels of the user can also face the professional interface.

ERP with a powerful information processing function. In the information times, the enterprise needs to deal with every day of countless information; simply by hand operation of the way has been difficult to meet the requirements. And ERP system with its advanced intelligent processing function can for ordinary business according to the previous set good methods to solve alone will filter out exceptions for staff to handle, improve working efficiency. At the same time, ERP also can automatic of a mass of data analysis results to make judgments, beyond the scope of the normal abnormal situation (including stand or fall two aspects) gives interpretation, instructions and analysis, warning its possible impact and give Suggestions and countermeasures. Therefore, if the electronic commerce as enterprise operation of the front desk, then in the enterprise internal control coordinates the ERP can become electronic business background. ERP is the foundation of enterprise development electronic business, in developing electronic commerce is the inevitable trend of the development of ERP, and the development of the electronic commerce also needs the support of the background with ERP and assistance. ERP and electronic commerce play between their respective advantages and complement each other, complement each other, to the enterprise management operation greatly, and between them the integration has become the development direction of the new era.

\section{ERP and E-Commerce Integration Model}

According to the ERP and the close relationship between the electronic business, according to the EB-ERP solutions, the building their integration model vender Fig. 1, more simple and clear analysis electronic commerce and the integration of the ERP realistic importance. Such as model shows, the middle of the big box represents the enterprise internal processes, and based on the operation mode in ERP, enterprise production management, financial management, marketing management, human resources management business process simultaneous operation. The Intranet (Intranet), through using $\mathrm{C}$ to $\mathrm{P}$ to electronic business model, between the departments of information can through the enterprise Intranet in first time sent to each business department, which can break the functional departments of time space boundary.

When in the face of customer, enterprise can build enterprise web portal, establishing the online store (e-Shop) to communication with their clients, to attract customers' interest and purchasing desire. Enterprise mainly uses the B to $\mathrm{C}$ mode of electronic business affairs, with the aid of Internet to contact with customers. To better to provide personalized service, enterprise then must use CRM management thinking to communicate with customer. By CRM to realize with customer's interactive marketing study consumer behavior, explore the customer value; Help customer self-service; Integrated Call Center to realize of the rapid response services. Might as well the hypothesis in the enterprise internal ERP system load on integrated a CRM module, which will make ERP extended the CRM function, between two patterns of seamless connection, can make the enterprise operating More effective, the integrated model may be realized after ERP software performance be ascension. When enterprise faces for suppliers and partners, they contact and communication mainly by Internet, extranet, adopts B to B's electronic business model. Enterprise 
can build e-commerce platform such as Internet Market, thus procurement, sales and other transactions in the Internet. Through the supply chain management to realize real-time collaboration of the whole logistics system; Distribute Resource Planning to implement working with sales, connecting the sales channel; realize zero stock. The ERP connect enterprise' traditional business and management, become the chain central of whole transaction. In this model, we can clearly see 5 kinds of flow movement in which information, capital from the client to the supplier flow, material flow, workflow, value-added flow in "supplier-business-customers" supply chain. Through the network and electronic business, the demand of the customers or the order can be zero wait to transfer to the whole supply chain, trading and supply almost occur at the same time; Through the network and electronic business, the boundaries of enterprise's inside and outside will gradually fuzzy until vanishing. Such model really reflect the thought that the network economy "take the customer as the center" and the essence of e-commerce "end-to-end".

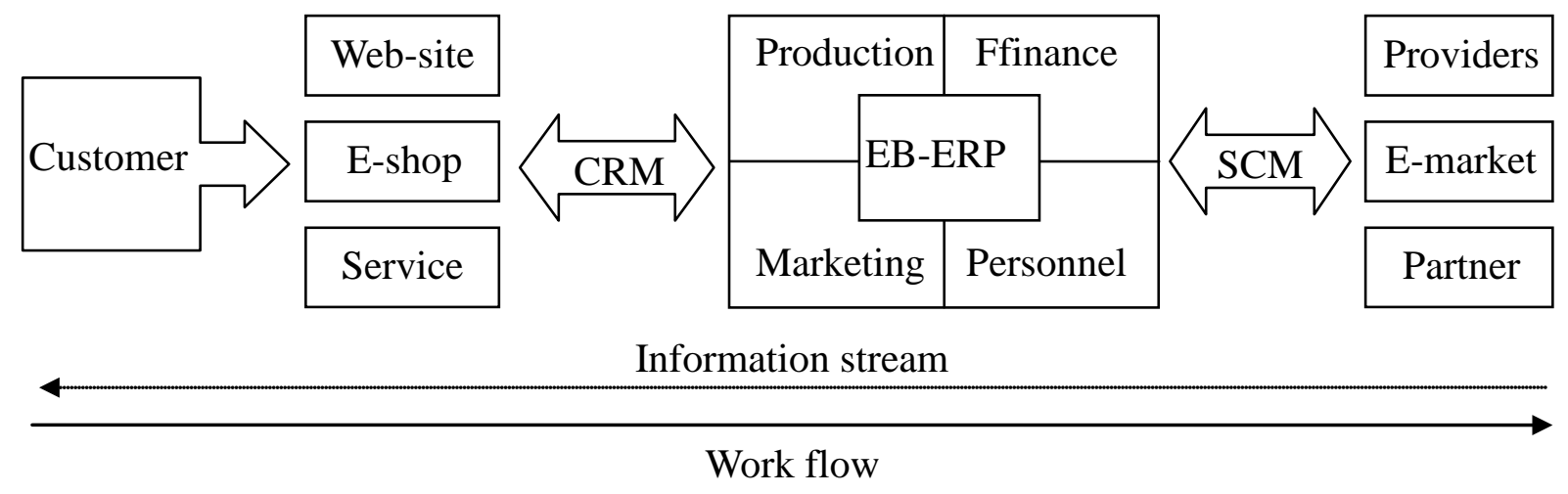

Fig. 1. Integration model on EB-ERP solutions

\section{Conception of the EB-ERP Module Analysis}

After ERP and electronic commerce integrated, enterprise operational emerge into ERP and electronic business integration rail, on the basis of the enterprise integration business process is no longer the main bodies of the independent. According to the structure of the integration model, let's discuss customer relationship management and knowledge management [5,6].

(1) Production-supply-marketing management under EB-ERP. Market competition intensifies, none enterprise can be best in all business, only the associated supply chain machinery-electronics complementary advantages can together increase competition strength. Therefore, the enterprise establishes extensive partnership with suppliers and distributors gradually. And form a stable of enterprise group alliance. Here were actually for the management of the enterprise reflects the SCM thinking, EB-ERP is design for the production-supply-marketing, through the interest to redistribute, make overall cost and efficiency to achieve optimal. Below discussion about EB-ERP mode integrated management of production, supply the plan and control, integration with warehouse inventory management, integration mode of money management aspects real-time. Production-supply-marketing integration mode resources optimization has extended to the whole your community. Enterprise can use resources include both internal resources, also external resources. EB-ERP production plan and control model the main use Internet/EB/EDI obtain relevant information, supply. Comprehensive utilization of internal and external resources, make the total cost and efficiency to achieve optimal. In the use of external resources, mainly embodies in outsourcing and external cooperation association two kinds of forms.

(2) Customer relationship management of EB-ERP. Customer relationship management is the new business model from "the customer as the center", it is a new management mechanism to improve the relationship between firm and customer. Same to ERP, CRM is a concept, an idea of management, is also a kind of technology, a kind of management software system, in this paper CRM is also a kind of enterprise operation mode. The CRM system is open source system which is the enterprise efficiency eternal theme. This paper consider take CRM into ERP and electronic commerce integration rail, can better realize enterprise operation customization. The call center of 
model is the means integration of communication interaction with the customer required, through which can fully satisfy customer consultation, purchase and service information needs. Call center of the CRM system techniques including E-mail, Web, telephone, fax and other way etc, so can bring the CRM system of the module into e-commerce. CRM system of automation service subsystem main sales, marketing, customer service three basic business process automation of information; Personalized service subsystem, mainly using data mining, decision aid and other advanced technology, to provide personalized service and to provide enterprises with decision aid information. The data warehouse can provide all kinds of CRM historical data.

(3) The knowledge management of EB-ERP. In the 21st century of knowledge economy age, knowledge is the most important strategic resources of enterprise, and knowledge management is strategic response when the enterprise in the face of the new situation. Knowledge management is the process that enterprise manage of knowledge resources, the goal is to make the enterprise employees identify, acquisition, development, decomposition, storage and transfer knowledge better, so that while each employee in the maximum to contribute its accumulated knowledge, can enjoy others knowledge, realize the knowledge sharing. Convert information into knowledge, use knowledge guide decision-making action, and then convert into the biggest management connotation. After ERP and electronic business integration, inevitably use various knowledge flows in the process of enterprise internal management cycle and supply chain management, and also collect and produce a lot of useful information. Through the information extraction, identification, analysis and induction converted the knowledge into the plan, organize, coordinate and control and so on a series of activities, the building of enterprise knowledge management.

\section{Conclusion}

This article through the analysis the correlation between ERP and electronic commerce, the paper construct the ERP and electronic business integration model, and the idea of analytical modules. Of course, this paper's integration is a kind of theoretical conception, did not realize in the enterprise applications. With the management theory of innovation and development of IT technology, ERP and electronic commerce their theory and technology will also continue to update, ERP and electronic commerce may appear more update. May achieve a big breakthrough in theory and technology for ERP and electronic business's integration, these are worth in the later theory research and management practice to continue to explore.

\section{References}

[1] F. R. Jacobs, F. C. 'Ted' Weston Jr. Enterprise Resource Planning (ERP)-A Brief History. Journal of Operations Management. 2007, 25(2): 357-363.

[2] Baidu Encyclopedia, "Enterprise Resource Planning (ERP)," http://baike.baidu.com/link?url=vCNCsepjnv1C_mrYrE165K3IdegSIS7wnWKMXdB4botbqaF PEX5GXTZXEhlgJ6ggqigQHoGOEGo4UB-xROGJu2IE7cq-9ULO76zqqY9xtxbE8Dw6FBPS Vq7PrsY9CIeTqN9mmdOQ20C4RB2tMjaFV_, 2015-5-6.

[3] Z. J. Wang, X. F. Xu and D. C. Zhan. Component Reuse Based Agile Reconfiguration for Enterprise Resource Planning (ERP) Systems in Manufacturing Enterprises. International Journal of Production Research. 2006, 44(23): 5107-5129.

[4] Y. Zhao, Y. S. Fan. Implementation Approach of ERP with Mass Customization. International Journal of Computer Integrated Manufacturing. 2007, 20(3): 160-168.

[5] B. Nico, G. J. Marx. Federated ERP-systems on the Basis of Web Services and P2P Networks. International Journal of Information Technology and Management. 2010, 9(1): 75-89.

[6] L. P. Ge, S. Vo . ERP Application in China: An Overview. International Journal of Production Economics. 2009, 122(1): 501-507. 